\section{Investment-Specific Technology Growth: Concepts and Recent Estimates}

\author{
Michael R. Pakko
}

T he rapid pace of productivity growth since the mid-1990s has been attributed to improvements in technology, particularly in the areas of information processing and communications. From e-mail and cell phones to inventory management and robotic manufacturing techniques, new ways of doing business - facilitated by the use of new types of capital equipment-have transformed the workplace.

However, traditional growth theory and growth accounting techniques - which emphasize the role of disembodied, neutral technological progress-are deficient in explaining the phenomenon of productivity growth driven by technology that is embodied in new types of capital equipment. Consequently, models of "investment specific" technological progress have gained prominence as a framework for evaluating the role of capital-embodied growth.

This article outlines a general model of investment-specific technological change, presents some new estimates, and examines the role that this type of technological progress has in explaining and predicting recent and prospective productivity growth trends.

\section{GROWTH THEORY WITH INVESTMENT- SPECIFIC TECHNOLOGY}

The idea that technology can be manifested in new, more efficient types of capital equipment has a long history in economics, dating at least to the "embodiment controversy" of Solow and Jorgenson in the 1960s. ${ }^{1}$ The rapid advancement of informationprocessing and communications technologies has renewed interest in the issue, inspiring the development of general equilibrium models that include investment-specific technological progress.

\footnotetext{
Michael R. Pakko is a senior economist at the Federal Reserve Bank of St Louis. Rachel Mandal, Mrinalini Lhila, and Athena Theodorou provided research assistance.

(c) 2002, The Federal Reserve Bank of St. Louis.
}

In this section, I describe a simple neoclassical growth framework - based on the model of Greenwood, Hercowitz, and Krussell (1997)—that incorporates this idea. In addition to balanced, neutral technological progress, the model includes a source of technological change that is associated with improvement in the quality of investment goods that becomes embodied in the productive capital stock. The model differs slightly from Greenwood, Hercowitz, and Krussell in two respects: First, the model in this paper treats equipment and nonresidential structures as two components of a single, composite capital good. In addition, the model described below includes a convex production possibilities frontier.

Our interest is in explaining economic growtha sustained increase in economic activity per capita. Hence, attention will focus on "steady state" growth paths in which all variables increase at constant (though possibly differing) rates.

\section{A Growth Model with Two Types of Technological Change}

A simple model that incorporates both types of technological change can be described as follows: The household sector is modeled as a representative agent who directly controls the production technology and owns the capital stock. Households supply labor inelastically to the production sector and make consumption-saving decisions by maximizing a stream of discounted utility over consumption:

$$
\sum_{t=0}^{\infty} \beta^{t} u\left(c_{t}\right)
$$

where $\beta<1$ is a constant discount factor and $c_{t}$ is (per capita) consumption. The momentary utility function is assumed to be of the constant relative risk aversion (CRRA) form $u\left(c_{t}\right)=c_{t}{ }^{1-\sigma} / 1-\sigma$.

Technology is typically incorporated directly into the production function: Output is produced using capital, labor, and the current state of technology. The production function is Cobb-Douglas and technology is specified in labor-augmenting form ${ }^{2}$ :

$$
Y_{t}=K_{t}^{\alpha}\left(Z_{t} L_{t}\right)^{1-\alpha}
$$

\footnotetext{
1 See, for example, Solow (1960) and Jorgenson (1966). Hercowitz (1998) describes the 1960s controversy in the context of contemporary models of investment-specific technology like the one described here.

2 Note that with a simple transformation of variables, $\breve{Z}=Z^{1-\alpha}$, the production function can be written in the alternative form $Y=\breve{Z} \cdot F(K, L)$, where $\breve{Z}$ is an index of total factor productivity.
} 


\section{Figure 1}

\section{Production Possibilities Frontier}

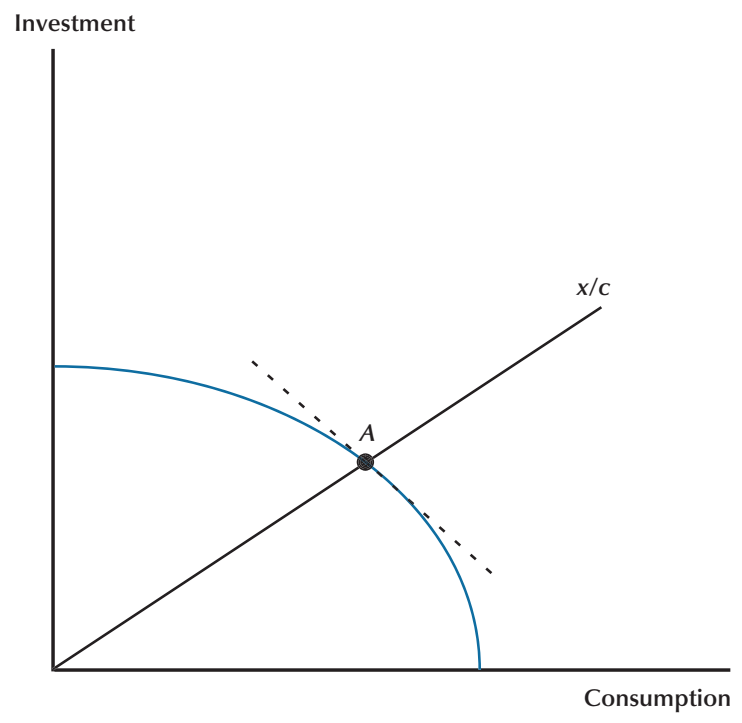

Here, $z_{t}$ is the technology index that directly enhances the productivity of labor, $L_{t}$, and indirectly that of capital, $K_{t}$, in the production of output, $Y_{t}$. Note that equation (2) can be written in terms of labor productivity as

$$
y_{t}=k_{t}^{\alpha} z_{t}^{1-\alpha}
$$

where the ratio of capital and output to labor are represented by lower case variables; that is, $k=K / L$ is the capital/labor ratio and $y=Y / L$ is labor productivity.

Writing equation (2) in terms of log-differences, productivity growth can be expressed as

$$
g_{y}=(1-\alpha) g_{z}+\alpha g_{k}
$$

where $g_{i}$, for example, denotes the growth rate of variable $i$. The "growth accounting" equation (3) shows that productivity growth can be decomposed into components representing "total factor productivity," $(1-\alpha) g_{z}$, and "capital deepening," $\alpha g_{z}{ }^{3}$

Investment-specific technology enters the model through the capital accumulation equation,

$$
k_{t}=(1-\delta) k_{t-1}+q_{t} x_{t},
$$

which states that the current productive capital stock consists of undepreciated capital from the previous period plus net investment, $q_{t} x_{t}{ }^{4}$ In equation (4) physical investment measured in consumption units, $x_{t}$, is enhanced by an index of the quality of newly produced capital goods, $q_{t}$. The product $q_{t} x_{t}$ represents investment as measured in efficiency units. The improvement in the quality of capital goods reflected in increasing values of $q_{t}$ is the driving force behind investment-specific technological change.

In the subsequent analysis of the growth properties of these two types of technology, we will assume that the economy's opportunities for producing consumption goods and investment goods is characterized by a nonlinear production possibilities frontier, $H\left(c_{t}, x_{t}\right)$, that is concave and invariant to scale. ${ }^{5}$ Figure 1 illustrates the tradeoff summarized by $H(\cong)$. For a given level of technology and existing capital, the economy is capable of producing any combination of consumption and investment lying on or below the production possibilities frontier (PPF). Points that lie outside the frontier are not feasible given the current state of technology, while points inside the frontier imply inefficient underutilization of resources. The optimal production combination will therefore lie on the frontier itself. The slope of the PPF at any given point shows the trade-off between consumption goods and investment goodsthat is, their relative price.

The durability of capital goods means that investment produces a stream of consumption goods into the future. Hence, the location of the optimal point on the PPF will depend on household preferences for substituting consumption between the present and the future (which, given the separable CRRA form of utility assumed, is time invariant in this model).

This combination of consumption and investment can be found from the representative agent's problem of maximizing utility (1) subject to the overall resource contraint,

$$
k_{t}^{\alpha} z_{t}^{1-\alpha}=H\left(c_{t}, x_{t}\right)
$$

and to the capital accumulation equation (4).

\footnotetext{
3 Using the notation from the previous footnote, the growth accounting equation (3) can be written explicitly in terms of the total factor productivity variable, $g_{y}=g_{\check{Z}}+\alpha g_{k}$.

4

The accumulation equation is often written so that there is a one-period time to build; that is, capital at time $t$ depends on investment at time $t-1$. The specification in this paper simplifies the exposition of capital growth and emphasizes the flow concept of investment.

5 Formally, the $H(\cdot)$ function is assumed to be homothetic. The nonlinear PPF can be thought of as shorthand for a more detailed model in which consumption goods and investment goods are produced in separate sectors, with costly transfer of factors between sectors.
} 
For a given level of technology, the representative household's maximization problem yields an optimal investment/consumption ratio, implying a specific equilibrium such as that shown as point $A$ in Figure 1. The slope of the dotted line shows the price of consumption goods relative to investment goods implied by this equilibrium.

\section{Case 1: Neutral Technological Change and Balanced Growth}

Suppose that the sole source of technology growth is $Z_{t}$, the index of labor-augmenting technological progress. For given quantities of labor and preexisting capital, an increase in $Z_{t}$ shifts the production possibilities frontier outward, as shown in Figure 2.

Because the expansion takes the form of a radial outward shift, both consumption and investment expand at the same rate as total output; that is, $g_{c}=g_{x}=g_{y} \cdot{ }^{6}$ Moreover, with $q$ constant, the capital accumulation equation (4) implies that capital grows at the same rate as investment, $g_{k}=g_{x}$. Hence, this type of growth is often referred to as "balanced," based on "neutral" technological progress. With investment and consumption growing at the same rate, the economy's growth path will be characterized by a constant $x / c$ ratio, as shown by the growth path running through points $A$ and $B$ in Figure 2 . Along this growth path, the slope of the PPF, representing the relative price of consumption and investment goods, is also constant.

From the growth accounting relationship (3), the shift in the PPF includes the direct effect of the increase in $z_{t}$ (represented in Figure 2 as movement point $A^{\prime}$ ) as well as a component associated with capital growth (accounting for the remaining shift to point $B$ in Figure 2). However, the role of capital deepening for this type of technological expansion is distinctly secondary. The direct effect of technology growth is an expansion of investment, which gives rise to a commensurate growth rate of capital. Indeed, substituting the relationship $g_{k}=g_{y}$ into the growth accounting equation (3), we find that the rate of output growth (as well as of consumption, investment, and capital growth) is equal to the rate of labor-augmenting technical progress. Although the growth accounting decomposition shows a role for capital deepening, there is no sense in which technological progress is "embodied" in capital growth. Rather, the capital component represents a passive response to "disembodied" technological

\section{Figure 2}

\section{Balanced Growth}

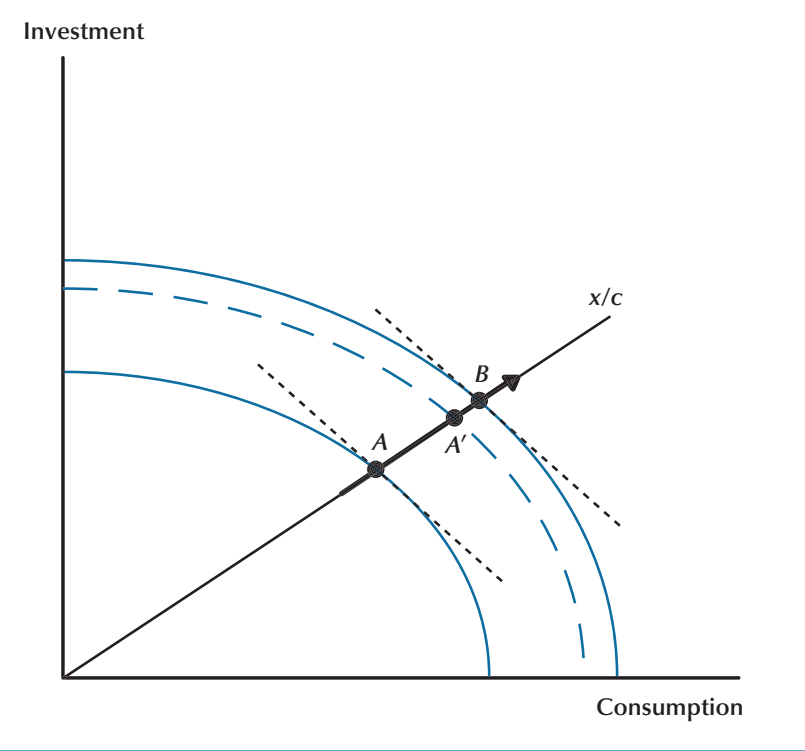

progress and does not comprise a truly independent source of economic expansion. ${ }^{7}$

\section{Case 2: Investment-Specific Technological Change and Capital- Embodied Growth}

Growth associated with investment-specific technological progress differs from neutral technology growth in several respects. First, note that $q_{t}$ does not appear directly in the economy's resource constraint, (5). Instead, the investment-specific technology index appears in the capital-accumulation equation and therefore operates through the capitaldeepening component of the growth accounting equation.

Investment-specific technological progress can be illustrated using a modified PPF framework, as shown in Figure 3. The vertical axis now measures "effective" investment, $q_{t} x_{t}$, incorporating the notion of improvement in the quality of investment goods. In Figure 3, the direct effect of an increase in $q_{t}$ is

\footnotetext{
6 This outcome is ensured by the scale-invariance property that is implied by the assumed homotheticity of utility and the PPF function.

7 Capital deepening does play an important role in the adjustment dynamics of the model. That is, when the economy is not on its steadystate growth path (King and Rebelo, 1993) or is in the transition between steady-state paths (Pakko, 2002b), capital deepening is the mechanism that moves the economy toward long-run equilibrium.
} 


\section{Figure 3}

\section{Investment-Specific Growth}

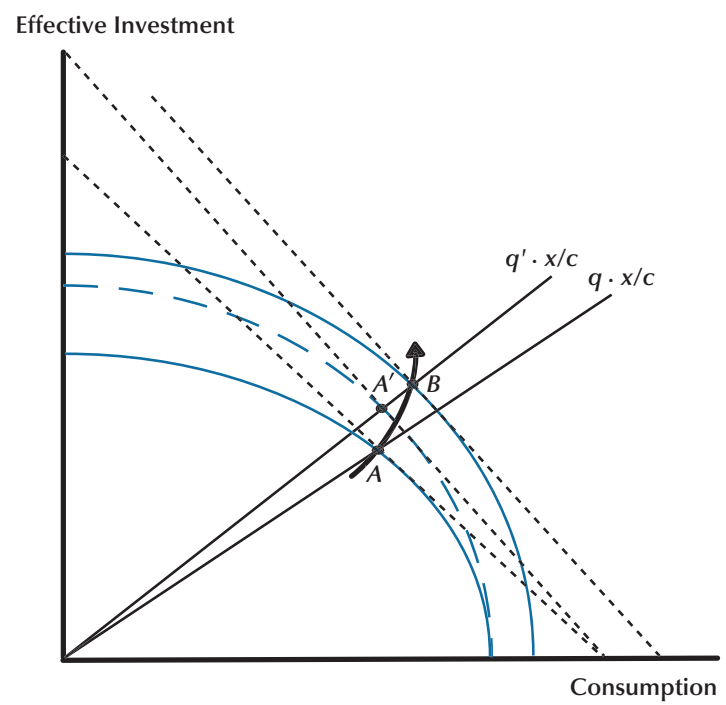

shown by the rotation of the PPF to the dashed line passing through point $A^{\prime}$. This twist in the PPF represents a change in the tradeoff between consumption and capital accumulation. The movement from point $A$ to point $A^{\prime}$ represents no change in $c$ or $x$ (or their ratio), but is simply a measure of the growth of "effective" capital that is made possible by the increase in $q$.

For this reason, the selection of an appropriate numeraire is important. If output were to be measured in terms of constant prices, the shift in the PPF attributable to the increase in $q$ would imply that output had risen for fixed inputs of labor and capital. Hence, growth accounting would incorrectly attribute part of the change to an increase in neutral technology, $z$. This mismeasurement would be even more severe if total output were measured in units of investment goods.

When the consumption good is taken as numeraire, total real income - as measured in consumption units along the horizontal axis-is left unchanged by the direct effect of growth in $q_{t}$. Appropriate measurement of investment-specific versus neutral technology growth therefore requires that the data be expressed in consumption units. In practice, this means that for growth accounting in the presence of investment-specific technical progress, nominal output and investment data should be deflated by a consumption price index. ${ }^{8}$

From the accumulation equation, an increase in $q_{t}$ has the effect of increasing the effective capital stock. In fact, when improvement in the quality of capital goods is accounted for, the growth rate of the capital stock will be the sum of the growth rates of physical investment and quality improvement,

$$
g_{k}=g_{x}+g_{q} .
$$

Hence, the indirect impact of investment-specific technology growth will be reflected in effective capital stock growth that shifts the PPF in Figure 3 outward. As was the case for neutral technological progress, the growth component of investmentspecific technological progress will be represented by a radial outward shift of the PPF that is characterized by a constant $x_{t} / c_{t}$ ratio and a common growth trend for output, consumption, and physical investment.

Substituting equation (6) and the relationship $g_{y}=g_{x}$ into (3), we obtain a relationship between productivity growth and the two sources of technology growth:

$$
g_{y}=g_{z}+\frac{\alpha}{1-\alpha} g_{q}
$$

In the presence of investment-specific technological progress, total economic growth will be equal to the rate of labor-augmenting technical change plus a component reflecting improvement in the quality of capital goods. Hence, investment-specific growth represents a channel through which technological progress is manifested through "embodiment" in productive capital.

Two features of the growth path passing through points $A$ and $B$ in Figure 3 are important for evaluating the role of investment-specific technology in the data. First, investment - when properly measured to include improvements in the quality of new capital goods - is predicted to grow faster than consumption along a steady-state growth path. In addition, the nature of the change in the tradeoff between consumption and investment, represented by the twist in the PPF, implies that the relative price of investment goods should be falling over time relative to consumption goods.

Figure 4 shows that these trends are, in fact, a characteristic of the data in the National Income and Product Accounts (NIPA). ${ }^{9}$ The ratio of investment

\footnotetext{
8 Greenwood, Hercowitz, and Krusell (1997) emphasize this point.

9 In Figure 4, "investment" corresponds to total nonresidential fixed investment and "consumption" is measured as nondurables plus ser vices less housing services.
} 
to consumption has risen persistently over the past half-century and has appeared to accelerate sharply in the past decade. Simultaneously, the price of investment relative to consumption has followed a clear downward trend since at least the late 1950s, with the rate of decline increasing since the 1980s.

\section{ESTIMATES OF INVESTMENT-SPECIFIC TECHOLOGICAL CHANGE}

The data presented in Figure 4 suggest that investment-specific technology growth has been an important feature of post-WWII trends in productivity growth. In order to quantitatively evaluate the role of investment-specific technology, however, it is important to carefully examine the issue of quality improvement for investment goods.

The measurement of quality change has always been important in the construction of the NIPA data. Quality characteristics of newly introduced goods are routinely incorporated into the data using socalled "matching models" that compare the attributes of new and existing products. In recent years, the BEA has implemented several revisions to its methodologies in order to account for the rapid rate of innovation in information processing, communications, and other high-tech sectors. In particular, so-called "hedonic regression techniques" have been applied to construct quantity and price indices that adjust for changes in quality over time. Among the more important applications of this approach, the BEA incorporates hedonic indices for computer equipment and purchased software, telephone switching equipment, cellular services, and video players, among others. ${ }^{10}$ Moreover, the BEA has even changed its aggregation methodology to more accurately measure the contribution of quality change to GDP growth: the adoption in 1996 of a chain-weighting methodology was intended to allow aggregates to track quality improvement better over time.

Nevertheless, some economists contend that a significant amount of quality change goes unmeasured in the official statistics, particularly in cases where quality improvement is more incremental. In a seminal 1990 study, The Measurement of Durable Goods Prices, Robert Gordon undertook to quantify the extent of this unmeasured quality change. Drawing data from a variety of sources, including special industry studies, Consumer Reports, and the Sears catalog, Gordon compiled a data set of more than 25,000 price observations. He constructed qualityadjusted price indexes for 105 different product categories, then aggregated the data to correspond

\section{Figure 4}

\section{NIPA Investment and Consumption: Relative Prices and Quantities}

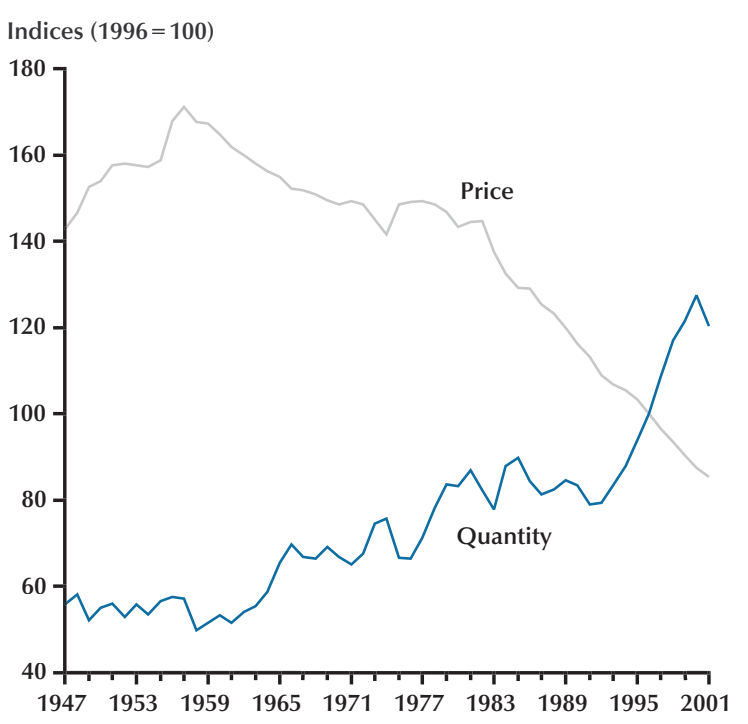

to the individual components of the BEA's measure of spending on producers' durable equipment. For each of 22 major categories of investment, Gordon calculated "drift ratios" representing the cumulative deviation of his adjusted price measures from the official data. The adjusted price components were then used to deflate nominal series, with the resulting real series aggregated to create a new qualityadjusted series for investment in durable equipment.

The bottom line of Gordon's study was that the official NIPA data (as constructed at the time) understated the true growth rate of real investment spending by nearly 3 percentage points per year over the period 1947-83. This quality adjustment for real investment spending is mirrored in the price deflator: the finding that quality-adjusted real investment spending is undermeasured implies that increases in the price of investment goods have been overstated. Unfortunately, Gordon's data set extends only through 1983.

\section{Quality Improvement for Equipment and Software Investment}

Previous estimates of investment-specific technology growth have been based on extrapolation of

\footnotetext{
${ }^{10}$ Landefeld and Grimm (2000) report that 18 percent of GDP is estimated using hedonic methods.
} 


\section{Figure 5}

\section{Growth Rates for Equipment and Software Investment}

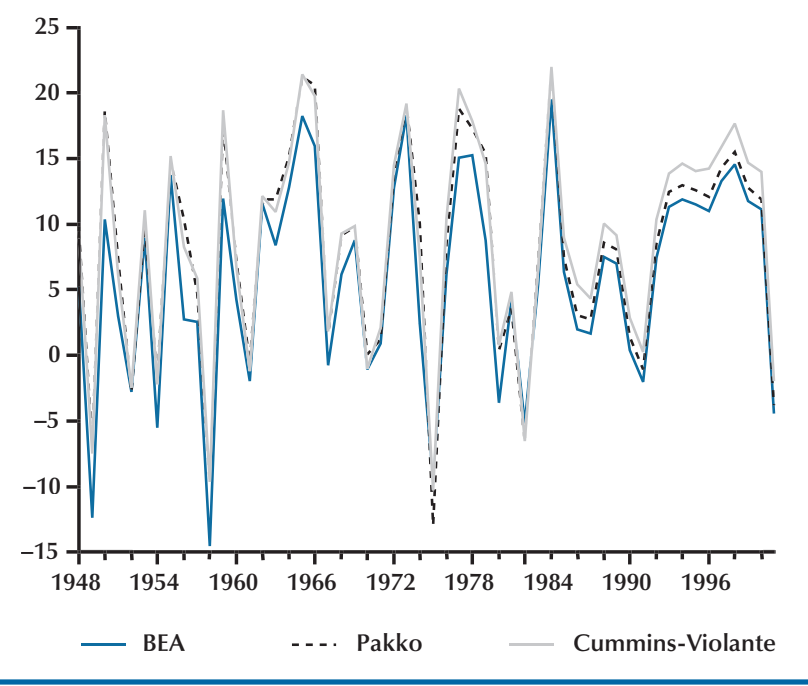

Gordon's aggregate data for series producers' durable equipment. For example, Greenwood, Hercowitz, and Krusell extended the Gordon data through 1990 by adding 1.5 percent to the growth rates of real investment spending for all categories except computers. Hornstein (1999) invoked a similar procedure to extend the estimate through 1997.

As BEA definitions and methodologies are updated and as relative shares of the components of equipment investment change over time, however, the simple extrapolation of Gordon's aggregate data becomes less satisfactory. Ideally, one would like to have extended data series at the disaggregated level of Gordon's original study. A less ambitious alternative is to extrapolate the drift ratios for each of Gordon's 22 major investment categories independently-accounting for changes in BEA definitions and methodology - then aggregate the extrapolated data to calculate a new, extended series. ${ }^{11}$

Two recent studies have followed variants of this procedure. Cummins and Violante (2002) estimate a simple time-series model that relates Gordon's quality-adjusted estimates and official BEA time series data for each of the individual investment categories. ${ }^{12}$ After estimating the coefficients of the model, Cummins and Violante extrapolate outof-sample estimates of quality-adjusted price levels for the period 1984-2000. ${ }^{13}$ Pakko (2002a,b) uses a simpler extrapolation technique: recognizing that the measurement bias documented by Gordon is larger in the earlier years of the sample period than the latter period, the Pakko estimates are based on a linear extrapolation of Gordon's drift ratios for the period 1973-83. The drift ratios were then applied to the official BEA price data to create extended quality-adjusted series.

Both sets of estimates were then aggregated to create a quality-adjusted measure of equipment investment for the period 1947-2000. Recent changes in BEA definitions and methodology complicate this procedure. One important innovation made in 1996 was the inclusion of software as an investment component. Gordon's data set did not include software, so both Pakko and Cummins and Violante used the official BEA measure for this component. Similarly, the BEA has devoted considerable effort to accurately measuring quality change for computers and peripheral equipment; hence, both studies assume that the bias found by Gordon in the vintage data has been eliminated in contemporary time series estimates for that component.

Figure 5 shows annual growth rates of these quality-adjusted series for aggregate equipment and software investment, along with the corresponding BEA measure. The two adjusted series track each other closely during the 1947-83 period, since both are based on Gordon's original data. ${ }^{14}$ The main source of divergence between the estimates over this period is the difference in aggregation methodologies: Cummins and Violante use the Törnqvist index approach advocated by Gordon, while Pakko uses the Fisher-ideal chain-weighting approach that has subsequently been adopted by the BEA. ${ }^{15}$

During the post-1983 period, the CumminsViolante series displays more rapid growth than the

\footnotetext{
${ }^{11}$ A disaggregated approach is preferable to a simple extrapolation of the aggregate trend for two reasons: First, several changes in the BEA's definitions and methodology have, for some components, eliminated or at least mitigated the measurement problems suggested by Gordon's study. In addition, the procedure of re-aggregating the quality-adjusted components using a chain-weighting methodology allows the role of changing expenditure shares over time to be appropriately accounted for.

12 The model posits that the adjusted price index is a function of a constant, a time trend, current and lagged values of the BEA time series, a cyclical indicator (lagged GDP growth), and an error term.

${ }^{13}$ Giovanni Violante was kind enough to provide the data from Cummins and Violante (2002).

${ }^{14}$ The growth rates of both adjusted measures exceed the official BEA growth rate by an average of about 2.75 percent per year over this period.

${ }^{15}$ The measures also differ in that the Pakko aggregate includes net sales of scrap equipment (excluding autos), as measured by the BEA.
} 


\section{Table 1}

\section{Growth Rates and Contributions to Growth of Nonresidential Fixed Investment}

\begin{tabular}{|c|c|c|c|c|c|c|c|c|c|}
\hline \multirow{2}{*}{$\begin{array}{l}\text { Source of } \\
\text { equipment } \\
\text { and software data }\end{array}$} & \multicolumn{3}{|c|}{$\begin{array}{l}\text { Nonresidential } \\
\text { fixed investment }\end{array}$} & \multicolumn{3}{|c|}{ Equipment and software } & \multicolumn{3}{|c|}{ Nonresidential structures } \\
\hline & 1950-2001 & 1950-1975 & 1976-2001 & 1950-2001 & 1950-1975 & 1976-2001 & 1950-2001 & 1950-1975 & 1976-2001 \\
\hline BEA & $5.17(100)$ & $4.59(100)$ & $5.75(100)$ & $6.26(80.3)$ & $5.30(70.9)$ & $7.23(87.8)$ & $2.96(19.7)$ & $3.48(29.1)$ & $2.44(12.2)$ \\
\hline Ad & $35(100)$ & $6.65(100)$ & $7.05(100)$ & $8.35(80.0)$ & 8.02 & 8.6 & $3.95(20.0)$ & $4.48(26.0)$ & 3.4 \\
\hline Adjusted 2 & $7.28(100)$ & $6.61(100)$ & $7.95(100)$ & $8.97(81.2)$ & $7.95(73.8)$ & $9.98(87.3)$ & $3.95(18.8)$ & $4.48(26.2)$ & $3.42(12.7)$ \\
\hline
\end{tabular}

NOTE: Numbers in parentheses refer to percent contributions to NFI growth.

Pakko series-due largely to assumptions regarding quality change in communications equipment. In 1997, the BEA introduced a quality-adjusted price index for telephone switching equipment and carried back these revisions to 1985 in the 1999 comprehensive revision of the national accounts. ${ }^{16}$ Because this component (the largest single component in the communications equipment category) was the predominant source of quality bias in Gordon's study, Pakko considers that the updated BEA data accurately measure quality change in that sector. On the other hand, Cummins and Violante note that the quality of other types of telecommunications equipment has been improving rapidly, so they opt to use their extrapolated estimate of quality bias from the Gordon data set (amounting to a drift ratio of nearly 7 percent). The two studies also differ somewhat in their treatment of automobiles, instruments and photocopy equipment, and office equipment other than computers. ${ }^{17}$ The effect of these differences in assumptions and methodology is that, for the 19842000 period, the Cummins-Violante series displays an average annual growth rate that is 2.7 percent higher than the official BEA data, while the growth rate of the Pakko series exceeds the BEA measure by only 1.1 percent per year. ${ }^{18}$

\section{Incorporating Quality Change for Nonresidential Structures}

In addition to equipment and software, another important component of the capital stock is the structures component-accounting for approximately 35 percent of nominal nonresidential fixed investment in the period 1948-2001. Gort, Greenwood, and Rupert (1999) examined the measurement of quality improvement in nonresidential structures and estimated that the official NIPA data understates real, quality-adjusted growth by approximately 1 percent per year.

To account for this source of investment-specific technology growth, I construct an adjusted measure of nonresidential structures by adding 1 percentage point to each year's growth rate in real nonresidential structures over the sample period of 1947-2001 (deducting 1 percent growth annually from its price index). The resulting real investment series and price index are then aggregated by chain-weighting with the adjusted measures of equipment and software spending to produce quality-adjusted decompositions for total private nonresidential fixed investment (NFI).

Table 1 shows the growth rates for these estimates of quality-adjusted NFI, along with the contribution of equipment and software and nonresidential structures to total growth. ${ }^{19}$ Two measures of qualityadjusted data are included: The first corresponds to the equipment and software data from Pakko. The second measure uses the Cummins-Violante data series. Both measures incorporate the quality improvement in structures suggested by Gort, Greenwood, and Rupert.

For the period 1950-2001, equipment and software spending accounted for more than 80 percent of the growth in total nonresidential investment. The relative contributions to growth have not been constant over time, however. During the first half

\footnotetext{
${ }^{16}$ Moulten and Seskin (1999).

${ }^{17}$ For more detail, see the appendix to Pakko (2002a).

${ }^{18}$ These growth spreads are used to extrapolate each of the adjusted series for the final growth observation from 2000 to 2001 (which was not included in either of the original series).

${ }^{19}$ The contributions to growth in Table 1 are calculated using the BEA's current methodology, as described in Moulten and Seskin (1999).
} 


\section{Figure 6}

\section{Investment-Specific Technology (q)}

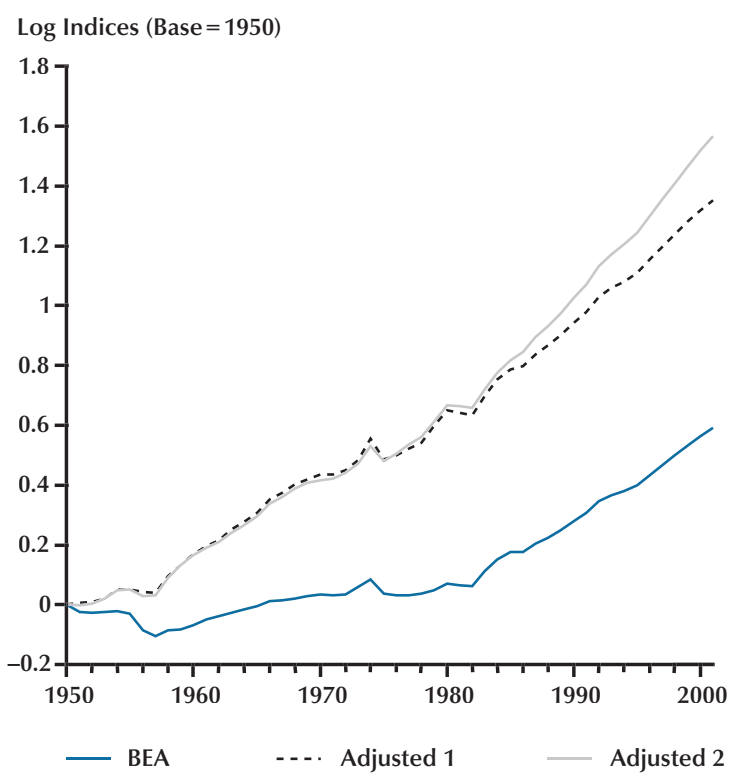

of the sample period, equipment and software investment accounted for less than 75 percent of total NFI growth, but accounted for 85 to 90 percent during the second half of the sample.

In previous literature, estimates of investmentspecific technology growth have treated the equipment and structures components separately. The estimates in this article use chain-weighted aggregates of both components, allowing flexibility to account for the shifting growth-shares, suggested by the pattern of growth contributions shown in Table 1.

\section{Growth Accounting with Investment- Specific Technical Progress}

The data for quality-adjusted investment and associated price indices form the basis for estimating the contribution of investment-specific technology to productivity growth. The first step is to calculate the index of investment-specific technology, $q$, as the price of consumption goods relative to (qualityadjusted) investment goods:

$$
q_{t}=P_{c} / \tilde{P}_{i},
$$

where $\widetilde{P}_{i}$ is a quality-adjusted price index for investment and $P_{c}$ is a consumption price index. Following the practice common in previous literature, the consumption price index used for this calculation covers nondurables and non-housing services. ${ }^{20}$ Durable goods are excluded from the consumption measure so as to avoid issues of quality improvement in that component.

Figure 6 shows this measure of $q$ for each of the three measures of investment prices constructed in the previous section. The data are indexed to a base year of 1950 in order to show their cumulative growth. The two quality-adjusted measures track each other closely through 1983, exceeding the growth rate of the unadjusted NIPA relative price by an average of 1.9 percent. For the period 1984-2001, the two adjusted series exceed the NIPA-based series by 1.0 percent (estimate 1, Pakko) and 2.0 percent (estimate 2, Cummins and Violante) per year.

The estimates of $q$, along with associated data for real investment, $x$, can be used to construct adjusted measures of the capital stock that account for embodied technological progress. The model suggests that real physical investment corresponds to nominal investment deflated by the consumption price index, $P_{i} I I P_{c}$. Effective investment, $q x$, is therefore given by $P_{i} I / \widetilde{P}_{i}$. In the NIPA data, with $P_{i}=\widetilde{P}_{i}$, this is simply the real investment series, so the BEA's data for private nonresidential fixed assets is an appropriate measure of the capital stock. For each of the adjusted investment series, $q x$ is the quality-adjusted real component from which a quality-adjusted measure of the capital stock can be derived.

The procedure used to construct quality-adjusted capital stock measures is as follows: First, I use the accumulation equation (4) and the NIPA series for investment and capital to back out a series of implied depreciation factors, $\left(1-\delta_{t}\right) .{ }^{21}$ These factors are then used to construct synthetic capital-stock series using a perpetual-inventory method-that is, by reconstructing the capital stock using equation (4) with the quality-adjusted investment data. Starting values for capital stocks in the base year used for these calculations, 1950, are initialized using the accumu-

\footnotetext{
20 The non-housing services data are constructed by chain-weighting PCE services with the additive inverse of the housing services component. The resulting series is then chain-weighted with nondurables consumption.

21 The BEA constructs measures of net stocks for individual components then uses chain-weighted aggregation to build aggregates. The use of these annual depreciation factors approximately adjusts for changes in the composition of the capital stock and total depreciation that arise from this procedure. For more information about the construction of the BEA's fixed-assets series, see Katz and Herman (1997).
} 


\section{Figure 7}

\section{Capital Stock Growth Rates}

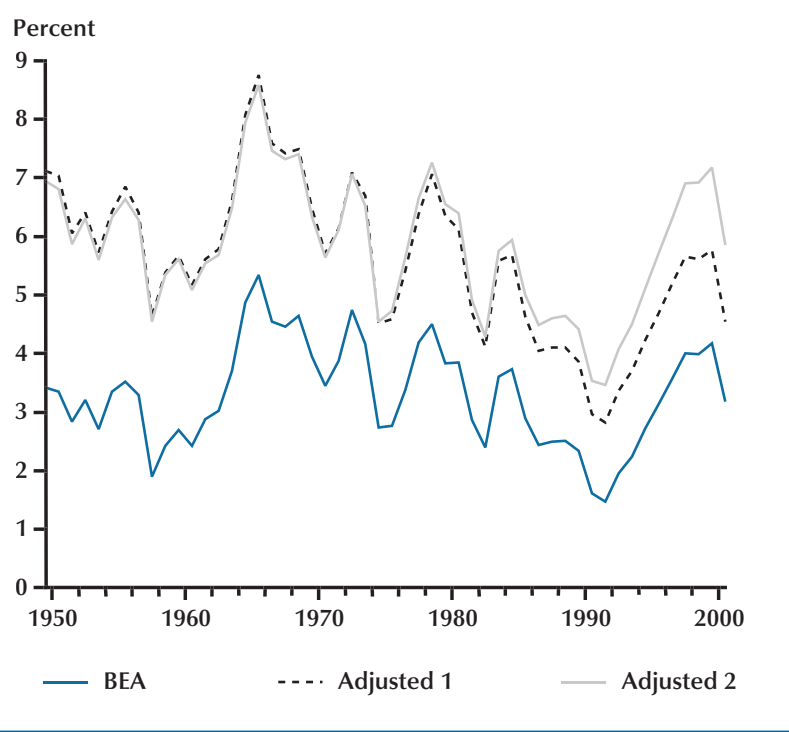

lation equation (4) to relate investment/capital ratios to the BEA data. ${ }^{22}$ The growth rates for these adjusted capital stock series, shown in Figure 7, exceed the official BEA measure by about 2.2 percent (Adjusted 1) and 2.5 percent (Adjusted 2) per year on average over the entire sample period.

Completion of the growth accounting exercise requires data for output and labor. In order for the data to correspond to a broad measure of labor productivity, output is taken to be gross domestic business product. ${ }^{23}$ Business sector hours-from the BLS labor productivity accounts-is used to measure labor input. These data series, along with the series for capital growth, can be used to back out measures of labor-augmenting technological change from the growth accounting equation (3).

Figure 8 shows measures of "neutral" technology that are derived from this procedure, where the series are expressed in log levels relative to a 1950 base in order to illustrate cumulative growth. Each of the series displays a clear decelleration beginning in the early 1970s, corresponding to the widely cited "productivity slowdown" that has prevailed for much of the subsequent period. For the two measures of $z$ derived from quality-adjusted data, the slowdown is particularly distinctive. After growth associated with investment-specific technology has been accounted for, the indexes of neutral technological progress have been nearly flat since 1970 .

\section{Figure 8}

\section{Neutral Technology (z)}

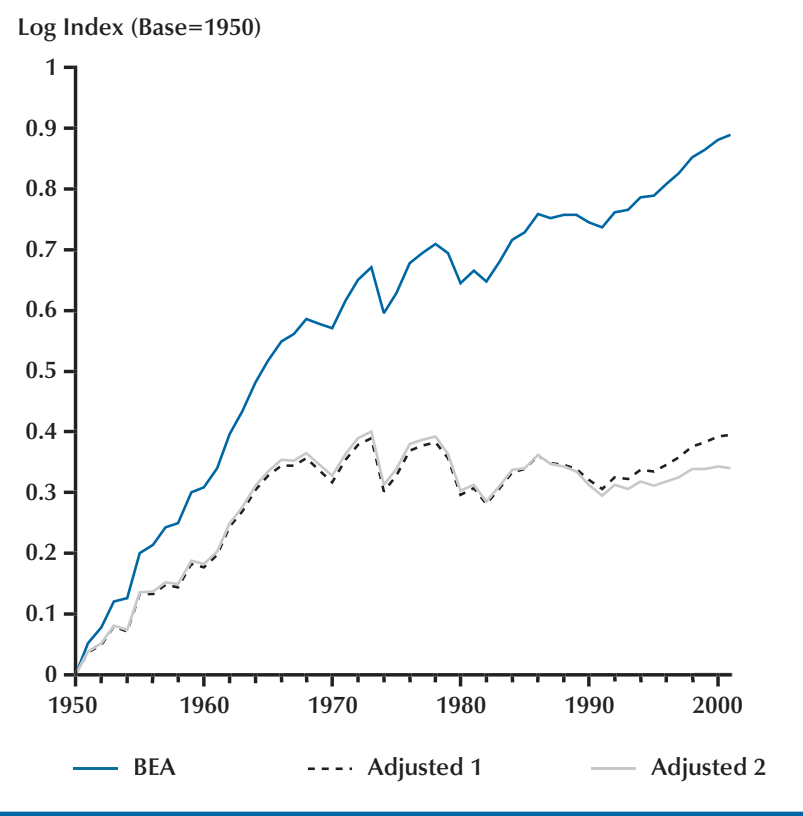

\section{Estimates of Neutral and Investment- Specific Technology}

Table 2 provides a summary of the two sources of growth, reporting the contributions to total potential growth provided by neutral and investmentspecific technological change as in equation (7). For comparability with previous studies, the data coverage for this decomposition begins with 1954 . Over the entire period from 1954 to 2001, the qualityadjusted measures show that the role of investmentspecific technological change has been considerable, accounting for 60 to 68 percent of total potential growth. Even the unadjusted NIPA data show a contribution of investment-specific technology that is 25 percent of the implied total.

The relative contributions of the two types of technology growth have not been constant over

\footnotetext{
22 In particular, the accumulation equation implies that $q x / k=$ $(1-\delta) /\left(1+g_{k}\right)$. The properties of the adjusted investment series and growth rates of investment-specific technology can therefore be used to relate the initial adjusted capital stock levels to the BEA data. This calculation yields initial values for the adjusted capital series of about one-third the level of the official data. Results are not very sensitive to small changes in the assumptions generating this relationship, however.

${ }^{23}$ In keeping with the model's implications for price measurement, real output is calculated by deflating nominal business sector GDP using the consumption price deflator.
} 
Table 2

Sources of Technological Progress, 1954-2001

1954-2001 $1954-1977 \quad 1978-2001$

\begin{tabular}{|c|c|c|c|}
\hline \multicolumn{4}{|l|}{ BEA } \\
\hline Neutral & 1.65 & 2.46 & 0.83 \\
\hline Investment-specific & 0.55 & 0.10 & 1.01 \\
\hline Total & 2.21 & 2.56 & 1.85 \\
\hline \multicolumn{4}{|l|}{ Adjusted 1} \\
\hline Neutral & 0.69 & 1.29 & 0.09 \\
\hline Investment-specific & 1.20 & 0.91 & 1.50 \\
\hline Total & 1.89 & 2.20 & 1.59 \\
\hline \multicolumn{4}{|l|}{ Adjusted 2} \\
\hline Neutral & 0.57 & 1.33 & -0.18 \\
\hline Investment-specific & 1.39 & 0.93 & 1.86 \\
\hline Total & 1.97 & 2.26 & 1.67 \\
\hline $\begin{array}{l}\text { Actual productivity } \\
\text { growth }\end{array}$ & 1.76 & 2.52 & 1.00 \\
\hline
\end{tabular}

the entire sample period, however. In the first half of the sample, 1954-1977, the quality-adjusted measures show that investment-specific technology contributes only about 38 percent to total potential. For the NIPA numbers, the measured contribution of investment-specific technology during this period is negligible. During the second half of the sample period, investment-specific technology overwhelmingly predominates. The second of these two adjusted measures (derived from Cummins and Violante) shows a negative contribution for neutral technology growth, while the first measure (based on Pakko) measures the contribution of neutral technology at only about 6 percent.

\section{Implications for Potential Productivity Growth}

The final line in Table 2 shows the actual growth rate of output per worker for the relevant sample periods. Over the entire period from 1954 to 2001, all three measures of technology change overpredict actual growth. As demonstrated in the breakdown between the first half and the second half of the sample, however, the overprediction is attributable to the more recent span of years. For the period 1954-77, the two adjusted measures slightly underpredict actual productivity growth. For the period 1978-2001, all three overpredict actual growth.

Of course, the measures of potential growth derived from the estimated technology series are approximated measures of long-run relationships, so it is not surprising that they do not precisely replicate actual growth over any given finite sample. During the period from the mid-1970s to the present, however, the magnitude and prevalence of the discrepancy suggest more than measurement or approximation error.

Recent research on the economic effects of introducing new technologies help to explain the apparent gap between measures of technology growth and productivity growth. The data suggest a rather dramatic change in the pattern of technology trends: the period of slow productivity growth in the 1970s and 1980s is associated with a change in the composition of technological progress from neutral to investment-specific technology.

Many economists have suggested that changes in trend technology growth - particularly for capitalembodied technologies - are associated with long transition periods during which productivity lags the rate of technological advance. Indeed, both Cummins and Violante (2002) and Pakko (2002b) focus on the adjustment of productivity growth to technological innovations. Cummins and Violante calculate that the "technology gap" - the gap between the productivity of the best technology and average productivity - rose from 15 percent in 1975 to 40 percent in 2000. This finding is in the spirit of "technology diffusion" models (e.g., Hornstein and Krusell, 1996; Jovanovic and MacDonald, 1994; Greenwood and Yorukoglu, 1997; Andolfatto and MacDonald, 1998; Hornstein, 1999), which posit that learning about the full potential of new technologies can generate long implementation lags as resources are channeled into the process of adapting new technologies into existing production structures. ${ }^{24}$ Pakko (2002b) shows that even in the absence of explicit diffusion lags, the adjustment of the capital stock to changes in technology growth trends give rise to long lags between technology and productivity - particularly when technology growth is investment-specific. These findings can be interpreted as suggesting that a great deal of the potential productivity improvement has yet to be fully incorporated into measured actual productivity growth.

\section{CONCLUSIONS}

A great deal of attention has recently been paid to the notion that rapid technological innovation

\footnotetext{
24 Another class of general growth models addressing the adaptation of "general purpose technologies" (e.g., Helpman, 1998) suggests similar lags.
} 
has been the driving force behind recent gains in U.S. productivity growth. However, the nature of these technology advances-being embodied in entirely new types of high-tech capital equipmentis not well explained by classical growth theory. This paper has reviewed a class of economic models featuring "investment specific" growth that explicitly describe a process in which new technologies are capital-embodied.

Recent estimates of the magnitude of this type of technology growth reported in this article suggest that over 60 percent of potential productivity growth over the past half-century can be attributed to investment-specific technology. Since at least the mid-1970s, the estimates suggest that the importance of investment-specific technology has increased sharply, accounting for practically all of the implied potential productivity gains.

However, measured productivity growth has fallen short of these estimates of potential. Recent research on the process of adapting new technologies to existing production frameworks gives reason for optimism about this finding. To the extent that rapid growth of investment-specific technological innovation has yet to be fully exploited, as the data suggest, technology-related gains in productivity should be expected to continue well into the future.

\section{REFERENCES}

Andolfatto, David and MacDonald, Glenn M. "Technology Diffusion and Aggregate Dynamics." Review of Economic Dynamics, April 1998, 1(2), pp. 338-70.

Cummins, Jason G. and Violante, Giovanni L. "InvestmentSpecific Technical Change in the United States (19472000): Measurement and Applications." Review of Economic Dynamics, April 2002, 5(2), pp. 243-84.

Gordon, Robert J. The Measurement of Durable Goods Prices. Chicago: University of Chicago Press, 1990.

Gort, Michael; Greenwood, Jeremy and Rupert, Peter. "Measuring the Rate of Technological Progress in Structures.” Review of Economic Dynamics, January 1999, 2(1), pp. 207-30.

Greenwood, Jeremy; Hercowitz, Zvi and Krusell, Per. "LongRun Implications of Investment-Specific Technological Change." American Economic Review, June 1997, 87(3), pp. 342-62. and Yorukoglu, Mehmet. "1974." Carnegie-
Rochester Conference Series on Public Policy, June 1997, 46(0), pp. 49-95.

Helpman, Elhanan, ed. General Purpose Technologies and Economic Growth. Cambridge, MA: MIT Press, 1998.

Hercowitz, Zvi, “The 'Embodiment' Controversy: A Review Essay.” Journal of Monetary Economics, February 1998, 41(1), pp. 217-24.

Hornstein, Andreas. "Growth Accounting with Technological Revolutions.” Federal Reserve Bank of Richmond Economic Quarterly, Summer 1999, 85(3), pp. 1-22.

and Krusell, Per. "Can Technology Improvements Cause Productivity Slowdowns?” NBER Macroeconomics Annual 1996. Cambridge, MA: MIT Press, 1996, pp. 209-59.

Jorgenson, Dale W. "The Embodiment Hypothesis." Journal of Political Economy, February 1966, 74(1), pp. 1-17.

Jovanovic, Boyan and MacDonald, Glenn M. "Competitive Diffusion.” Journal of Political Economy, February 1994, 102(1), pp. 24-52.

Katz, Arnold J. and Herman, Shelby W. "Improved Estimates of Fixed Reproducible Tangible Wealth, 1929-95." Survey of Current Business, July 1997, 77(5), pp. 69-92.

King, Robert G. and Rebelo, Sergio T. "Transitional Dynamics and Economic Growth in the Neoclassical Model." American Economic Review, September 1993, 83(4), pp. 908-31.

Landefeld, J. Steven and Grimm, Bruce T. "A Note on the Impact of Hedonics and Computers on Real GDP." Survey of Current Business, December 2000, 80(12), pp. 17-22.

Moulton, Brent R. and Seskin, Eugene P. "A Preview of the 1999 Comprehensive Revision of the National Income and Product Accounts: Statistical Changes." Survey of Current Business, October 1999, 79(10), pp. 6-17.

Pakko, Michael R. "The High-Tech Investment Boom and Economic Growth in the 1990s: Accounting for Quality." Federal Reserve Bank of St. Louis Review, March/April 2002a, 84(2), pp. 3-18.

, "What Happens When the Technology Growth Trend Changes?: Transition Dynamics, Capital Growth and the 'New Economy'." Review of Economic Dynamics, April 2002b, 5(2), pp. 376-407. 
Solow, Robert M. "Investment and Technical Progress," in Kenneth J. Arrow, Samuel Karlin, and Patrick Suppes, eds., Mathematical Methods in the Social Sciences. Palo Alto, CA: Stanford University Press, 1960. 